\title{
Distinct Levels of Human Anti-HLA Antibodies Induce Dif- ferent Biological Effects In Vitro on Human Umbilical Vein Endothelial Cells
}

\section{Juan J Mata*, Laura Moreno, Paula Arana, Silvia Chocarro, Amaia Gascue, Juana Merino and Cristina Moreno}

Department of Immunology, Clínica Universidad de Navarra, University of Navarra, Pamplona, Spain

\begin{abstract}
Objectives: Antibody-mediated rejection due to anti-donor HLA antibodies is a cause of chronic rejection and poor graft survival. The pathogenic role of these antibodies has been explained by their different effects on endothelial cells. Our objective was to study whether the levels of anti-HLA antibodies (measured by Luminex Single Antigen) in sera from alloimmunized patients correlate with the in vitro effects these antibodies induce on human umbilical vein endothelial cells.

Material and methods: We explored the role of anti-HLA antibodies present in human serum on the proliferative potential of human umbilical vein endothelial cells $(n=17)$ and studied the expression of adhesion molecules (P-selectin) in these cells $(n=13)$. Results were correlated with the HLA antibody levels measured by Luminex.

Results: The sera from alloimmunized patients inhibited endothelial cells proliferation and increased P-selectin expression compared to control sera $(\mathrm{p}<0.0001$ and $\mathrm{p}<0.001$, respectively). A relatively high level of anti-HLA antibodies was necessary to mediate the biological effects, with higher levels needed to affect proliferation (mean fluorescence intensity $=$ $23,219)$ than to induce changes in P-selectin expression (mean fluorescence intensity $=13,170$ ).
\end{abstract}

Conclusions: These data add information on the value of the detection of anti-HLA antibodies by Luminex and could contribute to clarifying some aspects of the pathogenic mechanisms of antibody-mediated rejection.

\section{Introduction}

Recent advances in different fields have substantially increased short-term graft survival. However, long-term graft survival is still very low, mostly due to chronic rejection [1-4]. Organ transplant rejection is caused by alloimmune responses, which primarily target HLA molecules [5-7]. The presence of Donor-Specific HLA Antibodies (DSA) is associated with Antibody-Mediated Rejection (AMR) and poor graft outcome [8-13]. Post-transplant Immunoglobulin G (IgG) DSA have been found to be a possible cause of allograft loss [6]. Everly, et al. demonstrated that $9 \%$ and $24 \%$ of patients will have allograft failure within 1 and 3 years from IgG DSA appearance, respectively [8]. The role of IgM DSA in the humoral immune response is not clarified. The same authors showed that IgM DSA alone does not pose a significant risk to allograft survival, but it is the first step in the development of the more problematic IgG DSA [14]. Other studies have found that non-DSA also were associated with graft failure [11,15], although not all published articles agree with this finding $[9,12,16]$. Several methods for detecting these antibodies have been described. Recent technologies, as Single Antigen Beads assay (Luminex technology), allow the detection of antibodies at very low levels compared to more traditional and less sensitive methods (complement-dependent cytotoxicity and flow cytometry crossmatch or ELISA) [17-21].

Furthermore, anti-HLA antibodies mediate different in vitro biological effects; anti-HLA class I monoclonal antibodies alter the cellular proliferation and survival of

\footnotetext{
*Corresponding author: Juan José Mata Molanes, Department of Immunology, Clínica Universidad de Navarra, Av. Pío XII, 36-31008 Pamplona, Spain, Tel: 34-948-255400, E-mail: jjmata@alumni.unav.es
}

Received: June 26, 2017: Accepted: September 12, 2017 : Published online: September 15, 2017

Citation: Mata JJ, Moreno L, Arana P, et al. (2017) Distinct Levels of Human Anti-HLA Antibodies Induce Different Biological Effects In Vitro on Human Umbilical Vein Endothelial Cells. J Cell Dev Biol 1(1):1-9

Copyright: (c) 2017 Mata JJ, et al. This is an open-access article distributed under the terms of the Creative Commons Attribution License, which permits unrestricted use, distribution, and reproduction in any medium, provided the original author and source are credited. 
Endothelial Cells (ECs) [22-25]. The possible in vitro effects of human HLA antibodies have also been studied. Purified IgG from human polyclonal anti-HLA serum preserves ECs from antibody-mediated complement-dependent damage and promotes proliferation and signal induction [26-29]. Some studies have investigated the role of human anti-HLA whole serum in modifying gene expression in ECs, which could be related to graft prognosis [30-31].

The above-mentioned effects of HLA antibodies have been connected to the pathogenic mechanisms of AMR $[32,33]$. More recently, the role of infiltrating cells in grafts has been considered more carefully to explain AMR [3436]. The adhesive potential of ECs increases after incubation with anti-HLA antibodies through the expression of $\mathrm{P}$-selectin. This mechanism results in monocyte adhesion to the endothelium and graft infiltration, which could be a clear contribution to the pathogenesis of AMR [34,35]. Most of these data refer to the effect of anti-HLA monoclonal antibodies and it is difficult to extrapolate these data to in vivo situations. We recently reported the effects of human alloimmunized sera on lymphocyte proliferation [37] and showed a correlation between the titer of anti-HLA antibodies and the biological effects on lymphocytes. Adsorption experiments also showed that the effect is HLA-mediated.

In the present study, we extend these data to a different model, studying the effect of human sera with high levels of anti-HLA antibodies on Human Umbilical Vein Endothelial Cells (HUVECs) to correlate the level of antibodies with the biological changes induced in these cells. We attempted to define the antibody levels mediating the in vitro biological effects on HUVECs. We measured changes in HUVEC proliferation and the expression of adhesion molecules (P-selectin). We take advantage of Luminex technology for a semiquantitative analysis of anti-HLA antibodies in serum. We show that diluted whole human serum from allosensitized patients inhibits the in vitro proliferation of HUVECs. Furthermore, the expression of P-selectin in HUVECs is increased by these antibodies. We also show that a higher level of HLA antibodies is necessary for the inhibition of HUVEC proliferation compared to the level necessary to induce P-selectin in these cells.

\section{Materials and Methods}

\section{Isolation and culture of HUVECs}

Human umbilical cords were obtained from healthy donors. The study was approved by the Ethics in Research Committee of the University of Navarra and written informed consent obtained from the donors prior to the study.
HUVECs were isolated from umbilical cords using a modified protocol previously described by Jaffe, et al. [38]. Under sterile conditions, the umbilical cord was infused with $15 \mathrm{ml}$ of $0.1 \%$ collagenase in PBS (warmed to $37^{\circ} \mathrm{C}$ ) (Gibco, Life Technologies Corporation, Grand Island, NY, USA) in the umbilical vein and maintained for 10 minutes at $37^{\circ} \mathrm{C}$. Briefly, the collagenase solution containing ECs was flushed from the cord by perfusion with $20 \mathrm{ml}$ of PBS and the effluent collected in a sterile $50 \mathrm{ml}$ conical tube. The cellular suspension was centrifuged at $624 \times \mathrm{g}$ for 8 minutes. Then, the cellular pellet was resuspended in $1 \mathrm{ml}$ of F12 K medium (ATCC, Manassas, VA, USA) supplemented with $10 \%$ Fetal Calf Serum (FCS) (Biochrom, Berlin, Germany), $100 \mathrm{U} / \mathrm{ml}$ penicillin (Life Technologies), $100 \mu \mathrm{g} / \mathrm{ml}$ streptomycin (Life Technologies), $30 \mu \mathrm{g} / \mathrm{ml}$ heparin (Hospira, Madrid, Spain), and stimulated with $5 \mu \mathrm{g} / \mathrm{ml}$ of Endothelial Cell Growth Supplement (ECGS) (Becton-Dickinson (BD), San Jose, CA, USA); this medium is referred to hereafter as "complete medium".

After isolation, ECs were seeded on $2 \%$ gelatin solution-precoated flask $\left(25 \mathrm{~cm}^{2}\right)$ (Sigma-Aldrich, St Louis, MO, USA) and cultured in complete medium $(4 \mathrm{ml})$. Cells were incubated at $37^{\circ} \mathrm{C}$ in a humidified incubator (5\% $\mathrm{CO}_{2}$ atmosphere). The culture medium was replaced after 24 hours, and then changed every 3 days until confluence. Cells were used in the initial passages $\left(2^{\text {nd }}-4^{\text {th }}\right)$ at a confluence of $80-90 \%$.

\section{Cell proliferation assay and phenotypic character- ization of HUVECs}

Upon confluence, the medium was removed and the adherent cell layer washed twice with $5 \mathrm{ml}$ of PBS. ECs were detached with $1 \mathrm{ml}$ of trypsin $(500 \mathrm{mg} / \mathrm{l})$ in EDTA $(200 \mathrm{mg} / \mathrm{l})$ (Lonza, Walkersville, MD, USA) and incubated for 3 minutes at $37^{\circ} \mathrm{C}$. The flask was flushed with $5 \mathrm{ml}$ of F12 K medium, and the effluent containing ECs was transferred to a sterile $10 \mathrm{ml}$ tube. The cells were centrifuged for 8 minutes at $624 \times \mathrm{g}$ and then adjusted to $2 \times$ $10^{6} \mathrm{cells} / \mathrm{ml}$ in complete medium. Next, $1 \times 10^{6}$ cells were incubated in $1 \mathrm{ml}$ of PBS with $4 \mu \mathrm{M}$ Carboxy Fluorescein Succinimidyl Ester (CFSE) (Invitrogen, Paisley, UK) for 10 minutes at $37^{\circ} \mathrm{C}$. Cold $\mathrm{F} 12 \mathrm{~K}$ medium $(5 \mathrm{ml})$ was then added for 5 minutes, and the cells centrifuged and washed two times with F12 K medium. Finally, the sample was adjusted to $1 \times 10^{6} \mathrm{cells} / \mathrm{ml}$ in complete medium.

An experimental model was established in which 1 $\times 10^{5}$ CFSE-labeled cells/well were seeded into six-well plates. In each experiment, ECs were incubated with different dilutions of pooled sera $(1: 40,1: 160,1: 320$, and $1: 640)$ from more than 10 highly alloimmunized patients on the renal transplant waiting list in $2 \mathrm{ml}$ of complete medium for 72 hours at $37^{\circ} \mathrm{C}$ and $5 \% \mathrm{CO}_{2}$. We take prof- 
it of these sera because of their high level of HLA antibodies and their poly specificity, allowing us to include in the study any umbilical cord available. ECs incubated in complete medium with serum from non-sensitized renal patients at the same dilutions and cells without ECGS were used as negative controls. Cellular proliferation and P-selectin expression were evaluated simultaneously after culture $72 \mathrm{~h}$ in 17 and 13 experiments, respectively, by combining 12 ECs with different dilutions of pooled sera with anti-HLA antibodies.

After incubation, cells were detached and washed as previously described. These cells were phenotypically characterized in regards to HLA expression and endothelial antigens. The phenotype of the cells was assessed by flow cytometry. To measure HLA expression, cells were labeled with $\mathrm{PE}$ mouse anti-human HLA-ABC $\mathrm{mAb}$ (clone G46-2.6; Pharmingen, $\mathrm{BD}$ ) and PE mouse anti-human HLA-DR mAb (clone L243; BD). To detect endothelial antigens (PECAM-1 and P-selectin), cells were labeled with $\mathrm{PE}$ mouse anti-human $\mathrm{CD} 31 \mathrm{mAb}$ (clone WM-59; BD) and PE mouse anti-human CD62P $\mathrm{mAb}$ (clone AK-4; $\mathrm{BD}$ ). In all experiments, PE mouse IgG1 k isotype control (clone MOPC-21; BD) was used as a negative control. After 20 minutes of incubation at room temperature in the dark, two PBS washing steps were performed and the ECs resuspended in $500 \mu \mathrm{l}$ of PBS. A total of 100,000 events were acquired with a FACSCanto II flow cytometer (BD). Analysis was performed with FACSDiva software v6.1.3 (BD). The cells under study were truly ECs showing an expression (median) of $95 \%$ of HLA-class I, $0 \%$ of HLA-DR, $100 \%$ of PECAM-1 and 13\% of P-selectin. Cellular proliferation was monitored by measuring the CFSE expression of the cultured cells using flow cytometry. Inhibition of cellular proliferation was calculated using the percentage of cellular proliferation with control serum as a reference; we considered cellular proliferation to be inhibited if the difference was $>20 \%$.

\section{HLA typing methods}

Total DNA was extracted from HUVECs using the QIAamp ${ }^{\circledR}$ DNA Blood Mini Kit (Qiagen GmbH, Hilden, Germany) according to the manufacturer's instructions. HUVECs were typed $(n=7)$ to ensure that at least one of the HLAs expressed by the cells was recognized by the pooled sera being studied in each particular culture. HLA-A and -B were determined using a PCR-based technique with AllSet $+{ }^{\mathrm{TM}}$ Gold SSP Typing Kits (Invitrogen).

\section{HLA antibody characterization}

Pooled sera were screened for anti-HLA antibodies using the Luminex LABScreen Mixed assay (\#LSM12 lot
019; One Lambda Inc, Canoga Park, CA, USA). The pool of sera was positive for all specificities of anti-HLA class I and class II antibodies. The specificity and intensity of anti-HLA class I antibodies present in each particular dilution of the pooled sera $(1: 40,1: 160$ and 1:320) were assessed using LABScreen Single Antigen Class I (\#LS1A04 lot 008; One Lambda Inc), which use single HLA antigen-coated beads and enable identification of immunoglobulin $\mathrm{G}$ alloantibody specificities against HLA-A, -B, $-C$ antigens. This test was performed according to the manufacturer's instructions. Normalized Mean Fluorescence Intensity (MFI) values > 1,000 were defined as positive reaction for anti-HLA class I and class II antibodies. When more than one antigen was recognized by a pool of sera, we utilized the MFI summative strategy to assign the antibody level present in the serum in relation to that cell as was proposed by us and others $[17,39,40]$. Levels of anti-HLA antibodies $>18,000$, measured as the sum of MFI, were considered high [37].

\section{Correlation between levels of anti-HLA antibod- ies and biological effects}

We analyzed the correlation between cellular proliferation and antibodies levels measured by Luminex Single Antigen Bead assay in 27 cells cultures by combining 9 ECs with dilutions 1:40, 1:160 and 1:320 of pooled of sera with anti-HLA antibodies. Moreover, in 17 experiments we evaluated the correlation between P-selectin expression and antibodies levels by incubating $6 \mathrm{ECs}$ with different dilutions of pooled of sera with anti-HLA antibodies (1:40, 1:160 and 1:320).

\section{Statistical analysis}

The percentage of cellular proliferation and P-selectin expression were provided as the median and range. We used the Mann-Whitney $U$ test to evaluate significant differences. The correlation between these two parameters and the level of anti-HLA antibodies was determined by the Spearman's rank correlation coefficient. For the analysis of $2 \times 2$ contingency tables, the chi-square test was used. In all cases, a $p$-value of $<0.05$ was considered significant. Statistical analyses were performed using IBM SPSS Statistics v20 software for Windows (SPSS, Inc., Chicago, IL, USA).

\section{Results}

\section{Human anti-HLA antibodies inhibit the cellular proliferation of HUVECs}

To study the influence of anti-HLA antibodies on cellular proliferation, we performed seventeen experiments by incubating ECs from twelve donors with pooled sera from alloimmunized patients. As shown in Figure 1 and Figure 2, cellular proliferation was significantly lower in 

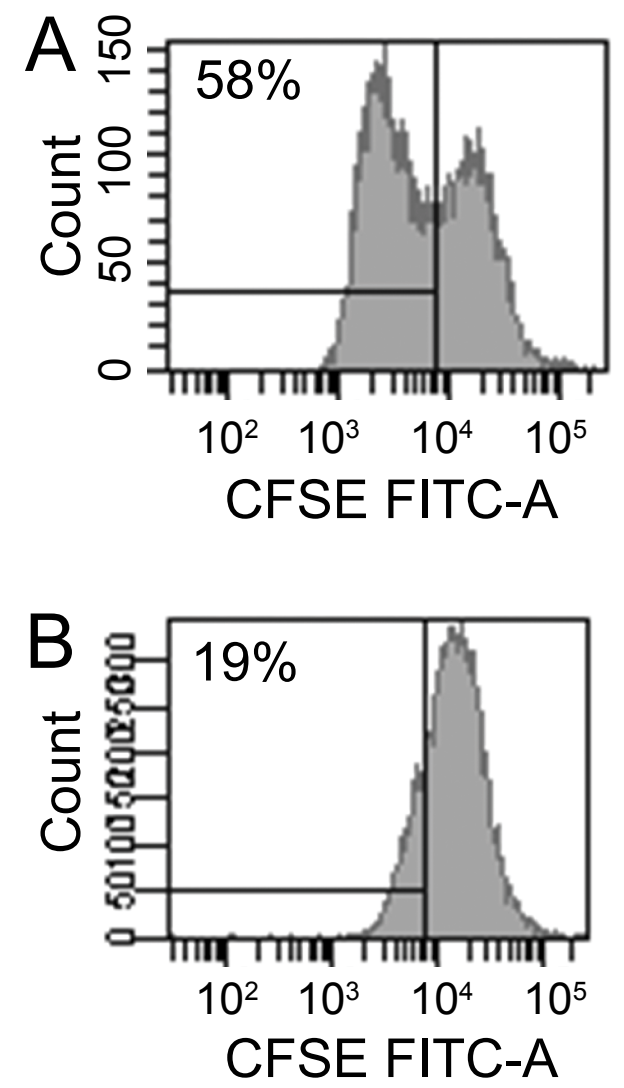

Figure 1: A representative experiment of cellular proliferation: A) Endothelial proliferation (58\%) with control serum 1:40 dilution; B) Percentage of cellular proliferation at 1:40 dilutions of serum with anti-HLA antibodies (19\%). This experiment shows a $67 \%$ inhibition of cellular proliferation induced by antiHLA antibodies. cultures with 1:40 dilutions of pooled sera (21.9\% (range $3.7 \%-43.4 \%) ; p<0.0001)$. The median MFI of HLA antibodies in these experiments was $61,877(29,005-67,289)$ (Table 1). The inhibitory effect on cellular proliferation was lost at higher serum dilutions: $39.7 \%(14.3 \%-74 \%)$, $49 \%$ (14.6\% - 76.6\%), and 48.7\% (14.7\% - 71.8\%) cellular proliferation at dilutions $1: 160,1: 320$, and $1: 640$, respectively.

We have investigated the correlation between the degree of inhibition of cellular proliferation and antibody levels measured by Luminex Single Antigen (LSA) against the HLA antigens expressed by different ECs in each serum dilution assays (1:40, 1:160 and 1:320) $(\mathrm{n}=$ 27). We found a strong association between the two parameters $(r=0.74, p<0.0001$; Figure 3$)$. Using a linear regression model, we calculated the level of anti-HLA antibodies required to produce this effect on ECs in vitro; antibodies inhibited endothelial proliferation by more than $20 \%$ at a MFI of 23,219 .

Table 2 presents the results based on this theoretical cutoff in a $2 \times 2$ table. When the strength of the anti-HLA antibodies was greater than the cut-off, 11/15 (73.3\%) experiment revealed inhibition of cellular proliferation. Only $2 / 12(16.6 \%)$ experiments revealed inhibition below the cut-off $(r=0.56, p=0.003)$.

\section{Human anti-HLA antibodies induce the expression of P-selectin in HUVECs}

In 13 experiments we studied the expression of P-se-

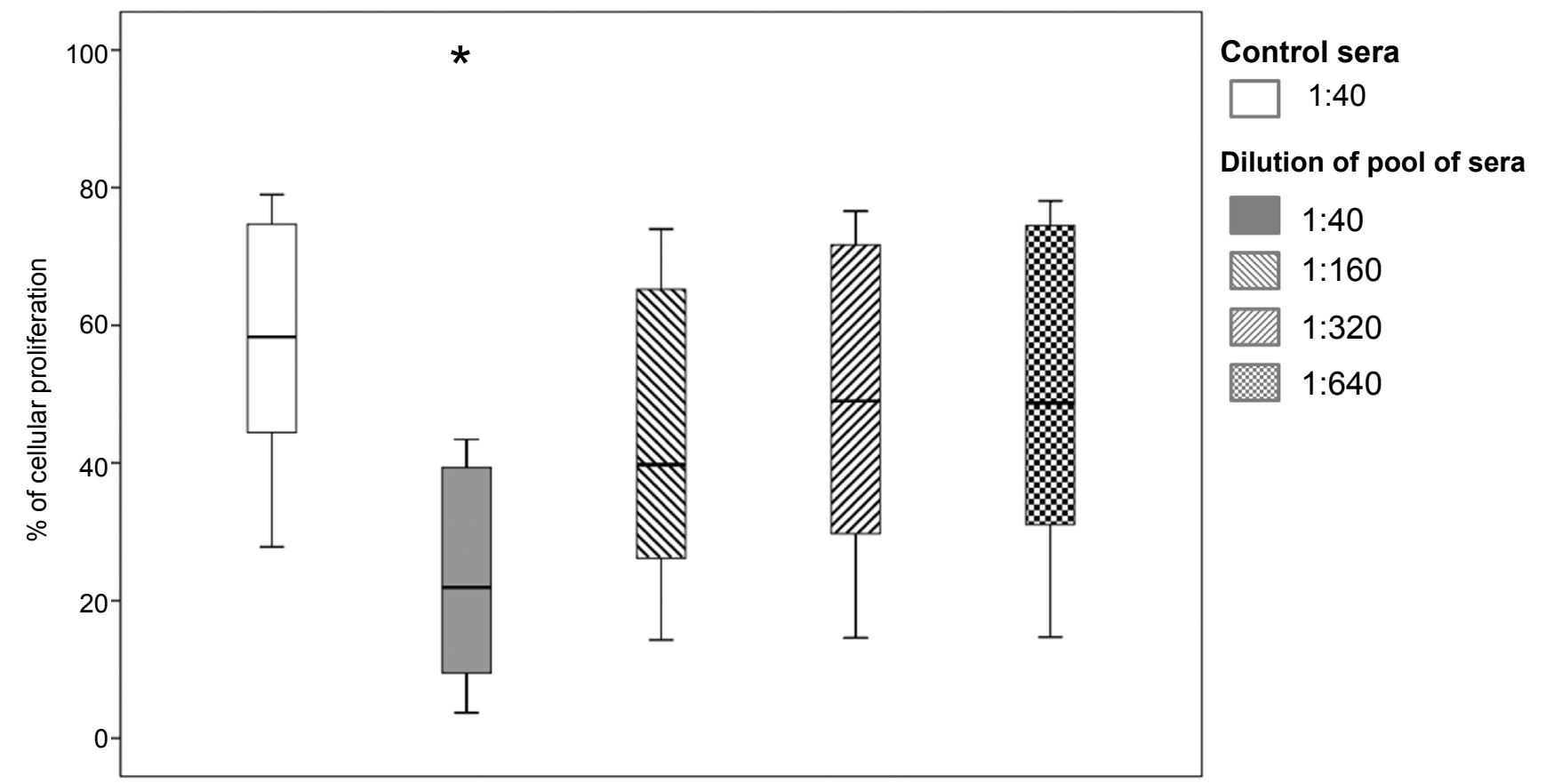

Figure 2: Cellular proliferation at different dilutions of pooled sera. ${ }^{*} p<0.0001$, Mann-Whitney $U$ test. 
Citation: Mata JJ, Moreno L, Arana P, et al. (2017) Distinct Levels of Human Anti-HLA Antibodies Induce Different Biological Effects in vitro on Human Umbilical Vein Endothelial Cells. J Cell Dev Biol 1(1):1-9

Table 1: Association between cellular proliferation data and HLA antibody levels.

\begin{tabular}{|l|l|l|}
\hline Dilution of pooled sera & Inhibition of cellular proliferation (\%) & Sum MFI LSA I \\
\hline $1: 40$ & 57.3 & 61,877 \\
\hline $1: 160$ & $(44.1-89.8)$ & $(29,005-67,289)$ \\
\hline & 14.5 & 26,645 \\
\hline $1: 320$ & $(0-37.0)$ & $(13,535-38,250)$ \\
\hline & 8 & 7,790 \\
\hline & $(0-23.2)$ & $(2,525-8,379)$ \\
\hline
\end{tabular}

*Sum MFI LSA I, sum of MFIs measured by Luminex Single Antigen class I assay.

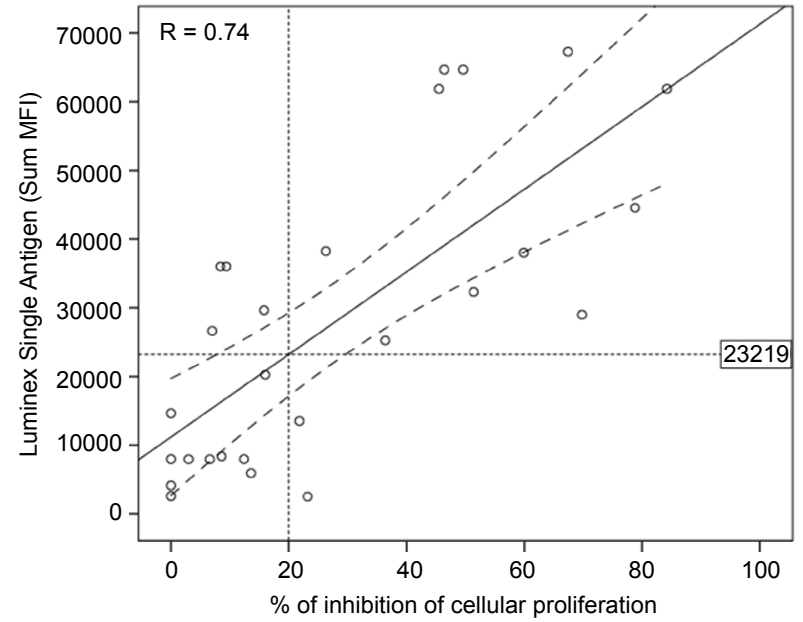

Figure 3: Correlation between the inhibition of cellular proliferation and antibody levels (MFI measured by Luminex Single Antigen Bead assay). Each dot represents MFI value of anti-HLA antibodies in serum (vertical axis) and the inhibition of cellular proliferation (horizontal axis) for each cell incubation with different dilutions of pooled sera $(1: 40,1: 160$ and $1: 320)(n=27)$.
Table 2: Luminex cut-off and cellular proliferation.

\begin{tabular}{|l|l|l|}
\hline Luminex single antigen & \multicolumn{2}{|l|}{$\begin{array}{l}\text { Inhibition of cellular } \\
\text { proliferation }\end{array}$} \\
\cline { 2 - 3 } & No $20 \%)$ \\
\hline $\mathrm{MFI}<23,219$ & 10 & Yes \\
\hline $\mathrm{MFI}>23,219$ & 4 & 2 \\
\hline
\end{tabular}

Chi-square test $(p=0.003)$; sensitivity, $84.6 \%$; specificity, $71.4 \%$.

lectin in ECs from 10 donors. We incubated the cells with dilutions of pooled sera from alloimmunized patients. A 1:40 dilution of pooled sera resulted in a significant increase in P-selectin expression compared to control sera (41.4\% (16.8\% - 58.5\%), $p<0.001$, Figure 4$)$. The median MFI of HLA antibodies in these experiments was 44,558 $(32,313$ - 61,877) (Table 3). Higher dilutions of pooled sera showed no differences with respect to controls in the expression of P-selectin.

We also studied whether P-selectin expression correlates with the level of anti-HLA antibodies present in dilutions of pooled sera $(n=17)$. Figure 5 shows that the data fit better in a quadratic regression (although also show statistical

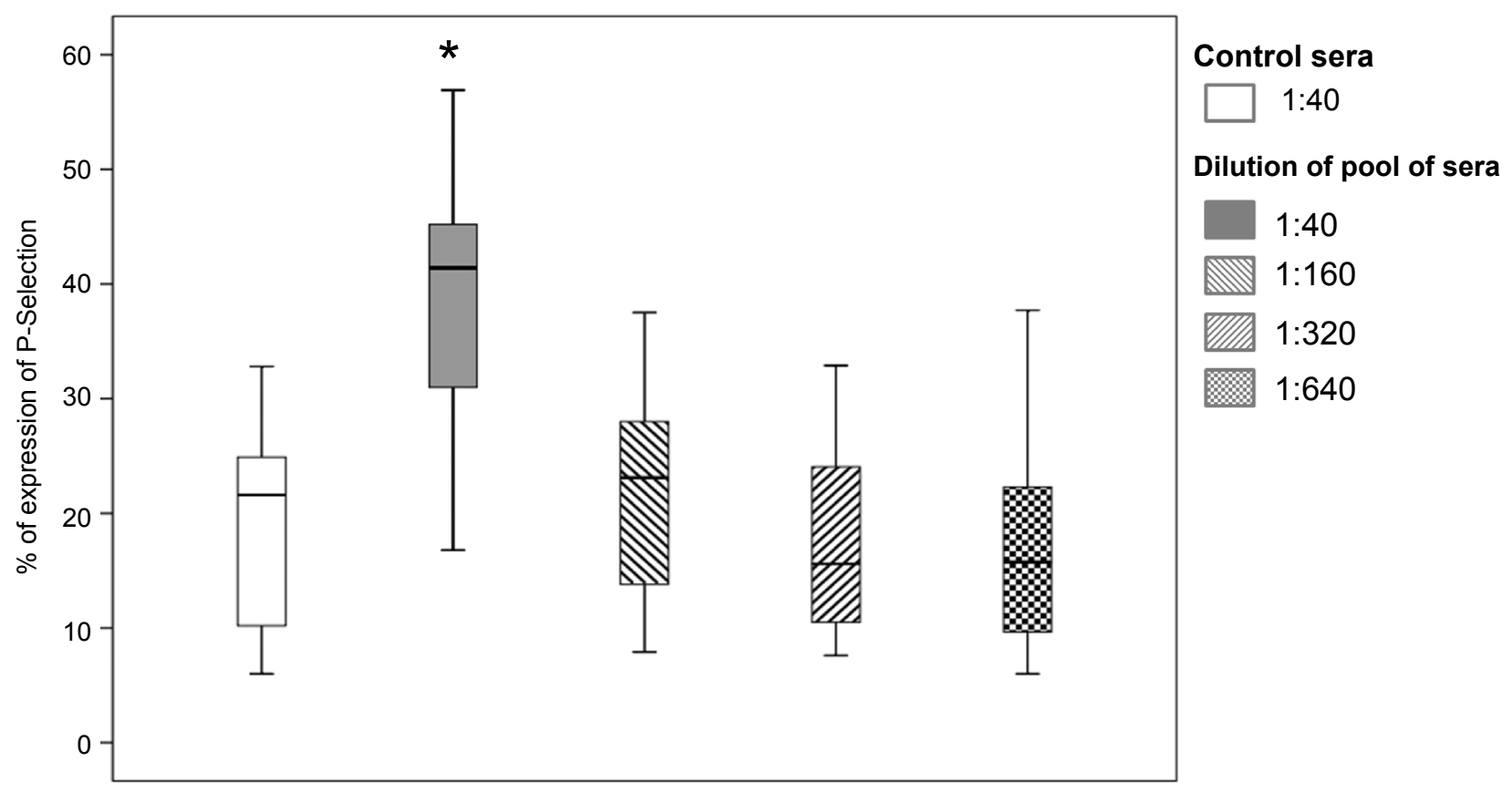

Figure 4: P-selectin expression at increasing serial dilutions of pooled sera. ${ }^{*} p<0.001$, Mann-Whitney $U$ test. 
Citation: Mata JJ, Moreno L, Arana P, et al. (2017) Distinct Levels of Human Anti-HLA Antibodies Induce Different Biological Effects in vitro on Human Umbilical Vein Endothelial Cells. J Cell Dev Biol 1(1):1-9

Table 3: Association between P-selectin expression and HLA antibody levels.

\begin{tabular}{|l|l|l|}
\hline Dilution of pooled sera & P-selectin expression (\%) & Sum MFI LSA I* $^{*}$ \\
\hline $1: 40$ & 41.4 & 44,558 \\
\hline & $(16.8-58.5)$ & $(32,313-61,877)$ \\
\hline $1: 160$ & 23.2 & 27,450 \\
\hline $1: 320$ & $(7.9-47.9)$ & $(14,649-38,250)$ \\
\hline & 15.9 & 6,950 \\
\hline & $(7.6-41.0)$ & $(2,590-8,379)$ \\
\hline
\end{tabular}

*Sum MFI LSA I, sum of MFIs measured by Luminex Single Antigen class I assay.

Table 4: Luminex cut-off and P-selectin expression.

\begin{tabular}{|l|l|l|}
\hline Luminex Single & \multicolumn{2}{|l|}{ Expression of P-selectin (> 25\%) } \\
\hline Antigen & No & Yes \\
\hline $\mathrm{MFI}<13,170$ & 5 & 1 \\
\hline $\mathrm{MFI}>13,170$ & 2 & 9 \\
\hline
\end{tabular}

Chi-square test $(p=0.009)$; sensitivity, $90 \%$; specificity, $71.4 \%$.

significance in a model of linear regression $(r=0.58, p=$ $0.013)$ ). A strong association was found between P-selectin expression and the MFI of HLA antibodies measured by LSA ( $r=0.71, p=0.007)$. Using this model, we calculated the MFI of anti-HLA antibodies necessary to produce these effects (MFI $=13,170$ for P-selectin expression $>25 \%$ and $\mathrm{p}<0.05$ ), which was lower than the level observed for the inhibition of cellular proliferation. When the strength of the anti-HLA antibodies was > 13,170 MFI, 9/11 (81.8\%) experiments revealed increased $\mathrm{P}$-selectin expression. Only $1 / 6(16.6 \%)$ experiments revealed increased P-selectin expression below the cut-off (Table $4 ; r=0.63, p=0.009$ ).

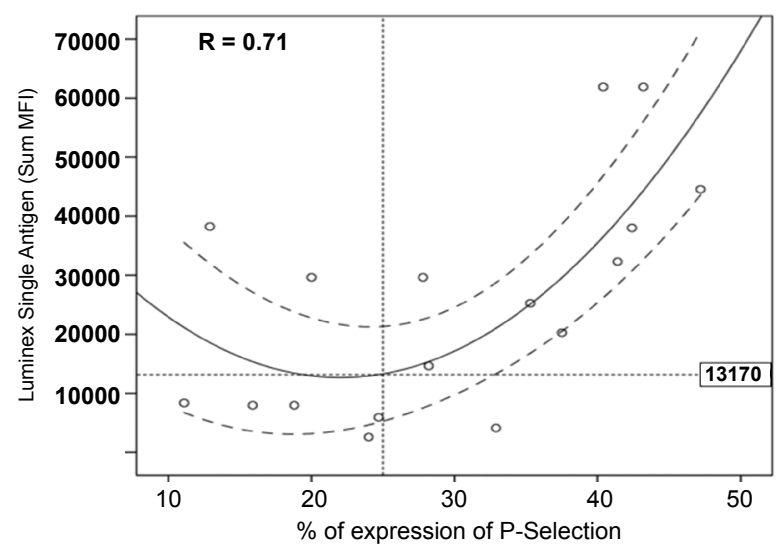

Figure 5: Correlation between the expression of P-Selectin and antibody levels (MFI measured by Luminex Single Antigen Bead assay). Each dot represents MFI value of anti-HLA antibodies in serum (vertical axis) and the P-selectin expression (horizontal axis) for each cell incubation with different dilutions of pooled sera $(1: 40,1: 160$ and $1: 320)(n=17)$.

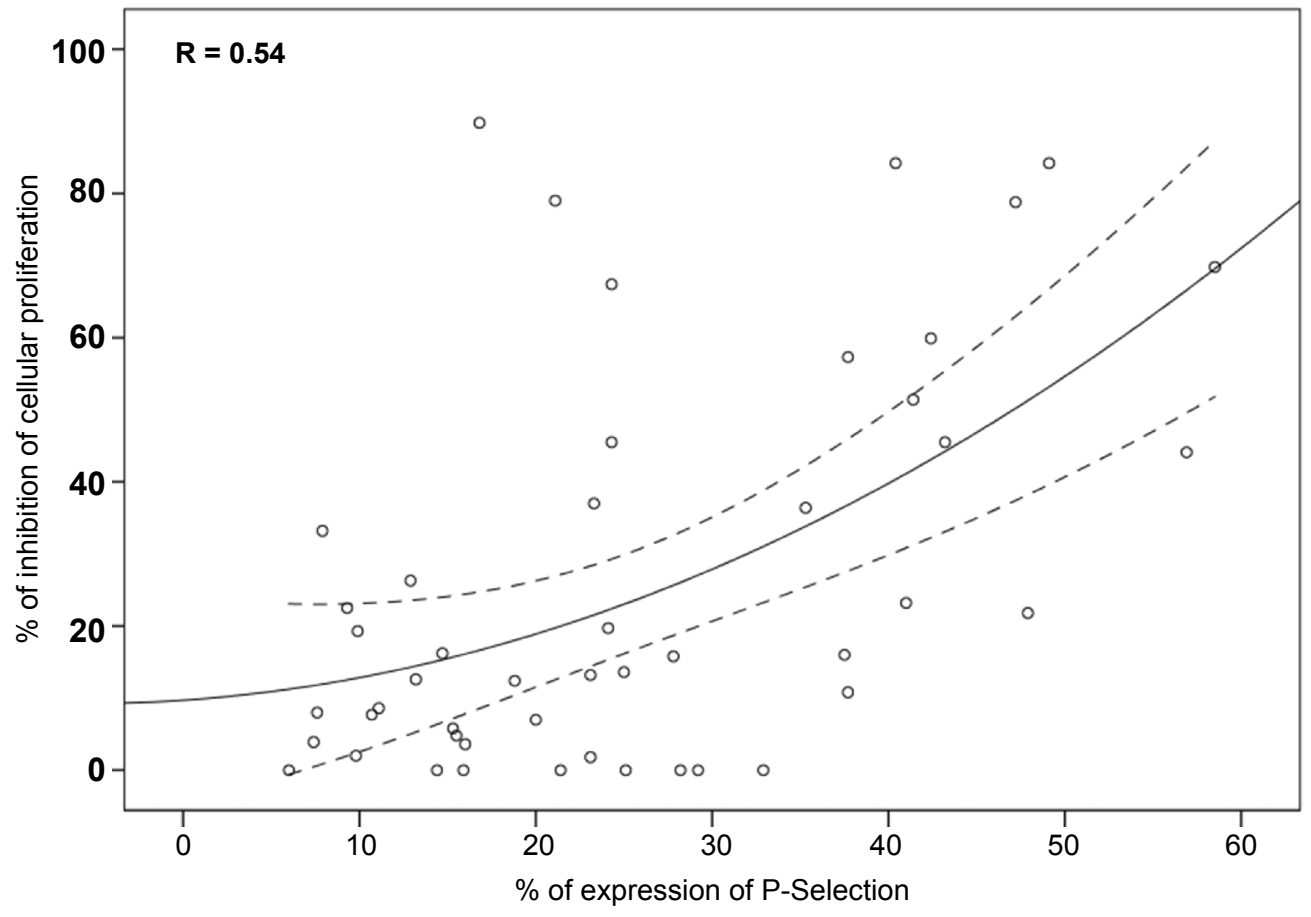

Figure 6: Correlation between the inhibition of cellular proliferation and P-selectin expression in ECs. Each dot represents the inhibition of cellular proliferation (vertical axis) and the P-selectin expression (horizontal axis) for each cell incubation with different dilutions of pooled sera with anti-HLA antibodies $(1: 40,1: 160,1: 320$ and 1:640) $(n=48)$. 
Finally, we correlated the results of HUVEC proliferation and $\mathrm{P}$-selectin expression measured simultaneously $(\mathrm{n}=48)$. Using a quadratic regression (Figure 6$)$, we observed a correlation between the inhibition of cellular proliferation and the expression of $\mathrm{P}$-selectin in $\mathrm{HU}$ VECs $(r=0.54, p=0.0001)$.

\section{Discussion}

The results of this study add information about the effects produced by anti-HLA antibodies present in serum from alloimmunized patients. We grew HUVECs in the presence of sera from alloimmunized renal patients awaiting transplantation. The proliferation of these cells is decreased due to a relatively high level of antibodies. In addition, anti-HLA antibodies induce a higher expression of P-selectin in HUVECs. We show a good correlation between inhibited proliferation and P-selectin expression and the level of antibodies measured by Luminex technology.

Very little is known about the effects of human anti-HLA antibodies and available data comes from studies using IgG isolated from human sera, which is not very well characterized in regards to the level of HLA antibodies $[28,29]$. Our work deals with total human sera as the source of HLA antibodies and HUVECs as target cells. The sera were studied by Luminex technology in order to semiquantitatively detect the level of anti-HLA antibodies. HUVEC have been object of study in different experimental models with very similar results to those obtained with other types of endothelial cells $[27,29,35]$.

The level of antibody is one of the factors implicated in the different biological effects produced by anti-HLA antibodies [23,33,41-43]. Our objective was not to deepen in the functional effects of alloantibodies but to study the correlation between the level of HLA antibodies and some of the effects already described. Therefore, we aimed to define the antibody levels necessary to mediate some of these effects. We grew ECs at very low ECGS concentrations to avoid excessive stimulation by growth factors and for better identification of the effects of anti-HLA antibodies. We show that the effects on HUVECs are observed only when the Luminex MFI reaches a particular level defined by the sum of MFI of antibodies directed to the different HLA antigens expressed by the cell under study [40]. The level of anti-HLA antibodies necessary to produce the described biological effects is different for each particular effect. High levels of antibodies are needed to inhibit HUVEC proliferation, whereas lower levels are enough to increase the expression of P-selectin. These data add information on the pathogenic mechanisms of AMR. Moreover, the detection of HLA antibody levels by LSA has been shown to correlate with other parameters and can be used as a substitutive in some special clinical situations, e.g., virtual cross-match $[39,40,44]$.
We think that we have enough evidence to assume that the described effects are mediated by anti-HLA antibodies. We reported recently that the effect of serum on lymphocyte proliferation was HLA-mediated, since adsorption of alloimmunized human serum with a particular cell population abolished inhibition of the proliferation of this cell population, but not proliferation of other cells with different HLA phenotypes [37]. Furthermore, the good correlation we found between the biological effects on HUVECs and the LSA level for HLA class I, as well as the very poor expression of HLA class II (HLA DR) on HUVECs, led us to the conclusion that the effects described in this paper are mediated exclusively by HLA class I and not by non-HLA antibodies. Moreover, we have published that human alloimmunized sera bind to cells and that a good correlation is obtained between the level of HLA antibodies MFI and FCXM positivity [40]. Thus, our data allow the identification of the antibody levels capable of mediating different biological effects on ECs, adding value to the detection of anti-HLA antibodies by LSA.

The generally accepted theory on the pathogenic mechanisms of AMR implies the induction of cellular proliferation by HLA antibodies [25]. However, as mentioned before, the in vitro response to HLA antibodies of both HUVECs and lymphocytes can vary. Although induction of cellular proliferation is commonly reported by anti-HLA antibodies we and others have published inhibition of lymphocyte proliferation on different experimental models by these antibodies $[37,41,45]$. We report here inhibition of HUVEC proliferation. This could be due to the characteristics of our model which includes low concentrations of ECGS, use of whole serum as the source of HLA antibodies and long period of culture (72 hours). The in vitro data may only partially reflect the in vivo situation. Besides, other factors that play a role in vivo could include the complement-fixing capacity of antibodies, although this point is currently discussed $[46,47]$. Other studies have demonstrated that organ transplant rejection can also be caused by non-HLA antibodies and Anti-Endothelial Cell Antibodies (AECA) [48]. Recently, AECA and anti-angiotensin II type 1 receptor antibodies have been associated with microvascular injury observed in AMR [49].

In addition to the inhibition of HUVEC proliferation by serum from alloimmunized patients, we documented a good correlation with the induction of P-selectin expression in these cells. Recently, the role of anti-HLA antibodies in the expression of P-selectin in ECs has been connected to the mechanisms of AMR [34-36]. The role of macrophage infiltration in AMR has been highlighted. This cellular infiltration could be favored by the induction of P-selectin in ECs $[34,35]$. These findings give 
more relevance to changes in the expression of adhesion molecules than to the induction of proliferative responses in the pathogenesis of AMR. Our results are in line with these views; we showed that anti-HLA human serum increases the expression of P-selectin in ECs while simultaneously inhibiting EC proliferation.

Our study adds new information for the validation of Luminex data and could contribute to a better understanding of some aspects of the pathogenesis of AMR.

\section{Acknowledgment}

A grant from PIUNA (University of Navarra) is gratefully acknowledged.

\section{Declaration of Interest}

The authors report no conflicts of interest. The authors alone are responsible for the content and writing of the paper.

\section{References}

1. Cosio FG, Gloor JM, Sethi S, et al. (2008) Transplant glomerulopathy. Am J Transplant 8: 492-496.

2. El-Zoghby ZM, Stegall MD, Lager DJ, et al. (2009) Identifying specific causes of kidney allograft loss. Am J Transplant 9: 527-535.

3. Bentall A, Cornell LD, Gloor JM, et al. (2013) Five-year outcomes in living donor kidney transplants with a positive crossmatch. Am J Transplant 13: 76-85.

4. Lee P, Zhu L, Terasaki PI, et al. (2009) HLA-specific antibodies developed in the first year posttransplant are predictive of chronic rejection and renal graft loss. Transplantation 88: 568-574.

5. Smith RN, Kawai T, Boskovic S, et al. (2008) Four stages and lack of stable accommodation in chronic alloantibody-mediated renal allograft rejection in cynomolgus monkeys. Am J Transplant 8: 1662-1672.

6. Terasaki PI, Cai J (2005) Humoral theory of transplantation: further evidence. Curr Opin Immunol 17: 541-545.

7. Valenzuela NM, Reed EF (2011) The link between major histocompatibility complex antibodies and cell proliferation. Transplant Rev (Orlando) 25: 154-166.

8. Everly MJ, Rebellato LM, Haisch CE, et al. (2013) Incidence and impact of de novo donor-specific alloantibody in primary renal allografts. Transplantation 95: 410-417.

9. Ginevri F, Nocera A, Comoli P, et al. (2012) Posttransplant de novo donor-specific HLA antibodies identify pediatric kidney recipients at risk for late antibody-mediated rejection. Am J Transplant 12: 3355-3362.

10. Kimball PM, Baker MA, Wagner MB, et al. (2011) Surveillance of alloantibodies after transplantation identifies the risk of chronic rejection. Kidney Int 79: 1131-1137.

11. Lachmann N, Terasaki PI, Budde K, et al. (2009) Anti-human leukocyte antigen and donor-specific antibodies detected by Luminex posttransplant serve as biomarkers for chronic rejection of renal allografts. Transplantation 87: 1505-1513.
12. Wiebe C, Gibson IW, Blydt-Hansen TD, et al. (2012) Evolution and clinical pathologic correlations of de novo donor-specific HLA antibody post kidney transplant. Am J Transplant 12: 1157-1167.

13. Willicombe $M$, Brookes $P$, Sergeant R, et al. (2012) De novo $D Q$ donor-specific antibodies are associated with a significant risk of antibody-mediated rejection and transplant glomerulopathy. Transplantation 94: 172-177.

14. Everly MJ, Rebellato LM, Haisch CE, et al. (2014) Impact of IgM and IgG3 anti-HLA alloantibodies in primary renal allograft recipients. Transplantation 97: 494-501.

15. Susal C, Wettstein D, Dohler B, et al. (2015) Association of kidney graft loss with de novo produced donor-specific and non-donor-specific HLA antibodies detected by Single Antigen testing. Transplantation 99: 1976-1980.

16. Hidalgo LG, Campbell PM, Sis B, et al. (2009) De novo donor-specific antibody at the time of kidney transplant biopsy associates with microvascular pathology and late graft failure. Am J Transplant 9: 2532-2541.

17. Amico P, Hönger G, Mayr M, et al. (2009) Clinical relevance of pretransplant donor-specific HLA antibodies detected by single-antigen flow-beads. Transplantation 87: 1681-1688.

18. Ferrari-Lacraz S, Tiercy JM, Villard J (2012) Detection of anti-HLA antibodies by solid-phase assay in kidney transplantation: friend or foe? Tissue Antigens 79: 315-325.

19. Ho EK, Vasilescu ER, Vlad G, et al. (2014) Detection of donor-specific-antibodies by solid phase assay and its relevance to complement-dependent-lymphocytotoxicity cross-matching in kidney transplantation. Hum Immunol 75: $520-523$.

20. Lefaucheur C, Loupy A, Hill GS, et al. (2010) Preexisting donor-specific HLA antibodies predict outcome in kidney transplantation. J Am Soc Nephrol 21: 1398-1406.

21. Patel AM, Pancoska C, Mulgaonkar S, et al. (2007) Renal transplantation in patients with pre-transplant donor-specific antibodies and negative flow cytometry crossmatches. Am J Transplant 7: 2371-2377.

22. Coupel S, Leboeuf F, Boulday G, et al. (2004) RhoA activation mediates phosphatidylinositol 3-kinase-dependent proliferation of human vascular endothelial cells: An alloimmune mechanism of chronic allograft nephropathy. J Am Soc Nephrol 15: 2429-2439.

23. Jin Y, Fishbein MC, Said JW, et al. (2004) Anti-HLA class I antibody-mediated activation of the PI3K/Akt signaling pathway and induction of $\mathrm{Bcl}-2$ and $\mathrm{Bcl}-\mathrm{xL}$ expression in endothelial cells. Hum Immunol 65: 291-302.

24. Jindra PT, Zhang X, Mulder A, et al. (2006) Anti-HLA antibodies can induce endothelial cell survival or proliferation depending on their concentration. Transplantation 82: S33-S35.

25. Li F, Zhang X, Jin YP, et al. (2011) Antibody ligation of human leukocyte antigen class I molecules stimulates migration and proliferation of smooth muscle cells in a focal adhesion kinase-dependent manner. Hum Immunol 72: 1150-1159.

26. Bian H, Reed EF (1999) Alloantibody-mediated class I signal transduction in endothelial cells and smooth muscle cells: Enhancement by IFN-y and TNF- $\alpha$. J Immunol 163: 1010-1018.

27. Bieri M, Oroszlan M, Farkas A, et al. (2009) Anti-HLA I antibodies induce VEGF production by endothelial cells, which 
Citation: Mata JJ, Moreno L, Arana P, et al. (2017) Distinct Levels of Human Anti-HLA Antibodies Induce Different Biological Effects in vitro on Human Umbilical Vein Endothelial Cells. J Cell Dev Biol 1(1):1-9

increases proliferation and paracellular permeability. Int $\mathrm{J}$ Biochem Cell Biol 41: 2422-2430.

28. Narayanan K, Jaramillo A, Phelan DL, et al. (2004) Pre-exposure to sub-saturating concentrations of HLA class I antibodies confers resistance to endothelial cells against antibody complement-mediated lysis by regulating Bad through the phosphatidylinositol 3-kinase/Akt pathway. Eur J Immunol 34: 2303-2312.

29. Smith JD, Lawson C, Yacoub MH, et al. (2000) Activation of NF-KB in human endothelial cells induced by monoclonal and allospecific HLA antibodies. Int Immunol 12: 563-571.

30. Iwasaki K, Miwa Y, Haneda M, et al. (2010) Significance of HLA class I antibody-induced antioxidant gene expression for endothelial cell protection against complement attack. Biochem Biophys Res Commun 391: 1210-1215.

31. Mannam VK, Lewis RE, Cruse JM (2013) The fate of renal allografts hinges on responses of the microvascular endothelium. Exp Mol Pathol 94: 398-411.

32. Jin Y, Jindra PT, Gong KW, et al. (2005) Anti-HLA class I antibodies activate endothelial cells and promote chronic rejection. Transplantation 79: S19-S21.

33. Jindra PT, Jin YP, Rozengurt E, et al. (2008) HLA class I antibody-mediated endothelial cell proliferation via the mTOR pathway. J Immunol 180: 2357-2366.

34. Valenzuela NM, Hong L, Shen XD, et al. (2013) Blockade of P-Selectin Is sufficient to reduce MHC I antibody-elicited monocyte recruitment in vitro and in vivo. Am J Transplant 13: 299-311.

35. Valenzuela NM, Mulder A, Reed EF (2013) HLA class I antibodies trigger increased adherence of monocytes to endothelial cells by eliciting an increase in endothelial P-Selectin and, depending on subclass, by engaging FcyRs. J Immunol 190: 6635-6650.

36. Yamakuchi M, Kirkiles-Smith NC, Ferlito M, et al. (2007) Antibody to human leukocyte antigen triggers endothelial exocytosis. Proc Natl Acad Sci U S A 104: 1301-1306.

37. Mata JJ, Burgos L, Delgado JA, et al. (2014) Relatively high levels of anti HLA antibodies (measured by Luminex Single-Antigen bead assay) are required to mediate inhibition of lympocyte proliferation induced by sera from alloimmunized renal patients. Ann Transplant 19: 652-659.

38. Jaffe EA, Nachman RL, Becker CG, et al. (1973) Culture of human endothelial cells derived from umbilical veins. Iden- tification by morphologic and immunologic criteria. J Clin Invest 52: 2745-2756.

39. Gloor JM, Winters JL, Cornell LD, et al. (2010) Baseline donor-specific antibody levels and outcomes in positive crossmatch kidney transplantation. Am J Transplant 10: 582-589.

40. Moreno C, Burgos L, Pérez-Robles C, et al. (2012) Predictive value of the Luminex single antigen panel for detecting flow cytometry cross-match positivity. Hum Immunol 73: 517-521.

41. Genestier L, Paillot R, Bonnefoy-Berard N, et al. (1997) Fas-Independent apoptosis of activated $\mathrm{T}$ cells induced by antibodies to the HLA class i alpha1 domain. Blood 90: 3629-3639.

42. Reed EF (2003) Signal transduction via MHC class I molecules in endothelial and smooth muscle cells. Crit Rev Immunol 23: 109-128.

43. Narayanan K, Jendrisak MD, Phelan DL, et al. (2006) HLA class I antibody mediated accommodation of endothelial cells via the activation of PI3K/CAMP dependent PKA pathway. Transpl Immunol 15: 187-197.

44. Zachary AA, Sholander JT, Houp JA, et al. (2009) Using real data for a virtual crossmatch. Hum Immunol 70: 574579.

45. Bregenholt S, Röpke M, Skov S, et al. (1996) Ligation of MHC class I molecules on peripheral blood T lymphocytes induces new phenotypes and functions. J Immunol 157: 993-999.

46. Peacock S, Kosmoliaptsis V, Bradley AJ, et al. (2014) Questioning the added value of luminex single antigen beads to detect $\mathrm{C} 1 \mathrm{q}$ binding donor HLA-specific antibodies. Transplantation 98: 384-386.

47. Valenzuela NM, McNamara JT, Reed EF (2014) Antibody-mediated graft injury: complement-dependent and complement-independent mechanisms. Curr Opin Organ Transplant 19: 33-40.

48. Dragun D, Philippe A, Catar R (2012) Role of non-HLA antibodies in organ transplantation. Curr Opin Organ Transplant 17: 440-445.

49. Philogene MC, Bagnasco S, Kraus ES, et al. (2017) Anti-Angiotensin II Type 1 receptor and anti-endothelial cell antibodies: A cross-sectional analysis of pathological findings in allograft biopsies. Transplantation 101: 608-615. 